\title{
Recovery of free volume in PIM-1 membranes through alcohol vapor treatment
}

\author{
Faiz Almansour ${ }^{1}$, Monica Alberto ${ }^{1}$, Rupesh S. Bhavsar ${ }^{2}$, Xiaolei Fan ${ }^{1}$, Peter M. Budd ${ }^{2}$, Patricia Gorgojo (凶) ${ }^{1}$ \\ 1 Department of Chemical Engineering and Analytical Science, School of Engineering, The University of Manchester, Manchester M13 9PL, UK \\ 2 Department of Chemistry, School of Natural Sciences, The University of Manchester, Manchester M13 9PL, UK
}

(C) The Author(s) 2021. This article is published with open access at link.springer.com and journal.hep.com.cn

\begin{abstract}
Physical aging is currently a major obstacle for the commercialization of PIM-1 membranes for gas separation applications. A well-known approach to reversing physical aging effects of PIM-1 membranes at laboratory scale is soaking them in lower alcohols, such as methanol and ethanol. However, this procedure does not seem applicable at industrial level, and other strategies must be investigated. In this work, a regeneration method with alcohol vapors (ethanol or methanol) was developed to recover permeability of aged PIM-1 membranes, in comparison with the conventional soaking-in-liquid approach. The gas permeability and separation performance, before and post the regeneration methods, were assessed using a binary mixture of $\mathrm{CO}_{2}$ and $\mathrm{CH}_{4}(1: 1, \mathrm{v}: \mathrm{v})$. Our results show that an 8-hour methanol vapor treatment was sufficient to recover the original gas permeability, reaching a $\mathrm{CO}_{2}$ permeability $>7000$ barrer.
\end{abstract}

Keywords polymer of intrinsic microporosity (PIM), PIM-1, physical aging, gas separation, vapor-phase regeneration

\section{Introduction}

Since the commercialization of the first membrane-based system for gas separation applications three decades ago, a wide range of polymers have been investigated and developed, but less than ten have made it to commercial use [1]. Non-network polymer of intrinsic microporosity (PIM-1), synthesized for the first time at the University of Manchester two decades ago [2], has shown great potential as a membrane material at laboratory scale, due to its high chemical, thermal and mechanical stability, as well as high gas permeability (arising from its high free volume) and

Received June 24, 2020; accepted August 3, 2020

E-mail: p.gorgojo@manchester.ac.uk fair selectivity values. All these properties also make it attractive for commercial gas separation applications $[3,4]$. However, as generally happens to high free volume polymers, PIM-1 is prone to lose the void space rapidly due to physical aging, which results in the loss of membrane performance over time. The polymer chains are initially packed in a non-equilibrium state, leaving excess free volume. Over time, loss of free volume occurs by the gradual rearrangement of the polymer chains towards an equilibrium state, leading to an increase of polymer density. As a consequence the permeability of the membrane is reduced, compromising its long-term stability. This effect is more pronounced at the beginning of its lifetime, with a significant decline in permeability, the rate of which decreases with time $[5,6]$. Similarly to other polymers [7], the rate of physical aging in PIM-1 membranes is also thickness-dependent, being faster in thin films compared to thicker films [8,9]. Other factors, such as temperature, pressure, atmosphere and storage conditions, also play an important role in the physical aging rate [10-12].

It is worth noting that several other solution-processable PIMs synthesized over the past few years have overcome the well-known Robeson 2008 upper bound for certain gas pairs $[13,14]$. However, as with PIM-1, they also suffer from physical aging [15-17], and PIM-1 is still the most investigated non-network PIM. Different approaches have been explored to prevent or minimize physical aging in PIM-1 membranes, including: 1) modification and synthesis of new polymer structures $[6,18], 2)$ post-modification treatments (e.g., thermal oxidative crosslinking [19], the use of supercritical $\mathrm{CO}_{2}$, and ultraviolet treatment [20]), and 3 ) addition of fillers to the polymer matrix, giving socalled mixed matrix membranes [21-23]. Physical aging is a reversible process, unlike others such as degradation, chemical aging and contamination that affect membrane properties irreversibly [1]. In some glassy polymers, such as polysulfone and polyimide, the membrane performance 
is recovered by annealing the sample above its glass transition temperature $\left(T_{\mathrm{g}}\right)$, followed by rapid quenching to room temperature [24]. However, in polymers with very high or undetectable $T_{\mathrm{g}}$, the group to which PIM-1 belongs, this is not possible [1]. In this case, the 'rejuvenation' of the membrane performance is typically undertaken by soaking the films in lower alcohols, such as methanol or ethanol $[8,12,13,25]$. Alcohols swell PIM-1, causing an enhancement of the molecular motion of the polymer chains that leads to an increase in the free volume of the polymer [26]. In addition, the alcohol treatment also flushes out any residual solvents and contaminants trapped within the polymer and erases the past processing history [12]. Similarly, other studies have reported the posttreatment of membranes with a range of solvents to enhance their performance in applications such as organic solvent nanofiltration [27,28], reverse osmosis [29], nanofiltration [30], ultrafiltration [31,32] and pervaporation [33].

Albeit soaking in alcohol is a simple procedure, which is typically done after membrane casting, it requires the removal of the membrane from the gas separation apparatus when it is used to recover permeability of aged membranes. This might be acceptable for small scale and fundamental studies, however, at the industrial level, this procedure would be completely unattainable; membrane modules used in gas separation are not designed to cope with liquid, and a treatment that does not require membrane dismantling would be desirable. Moreover, we envisage that the treatment with alcohol vapor would not cause any further disturbance in the gas separation system, and the use of an inert gas or air following the vapor treatment could eliminate any traces of alcohol vapor and leave the membrane module ready to use. Therefore, in this work we present an alternative that consists in exposing aged PIM-1 films to ethanol or methanol vapor four months after casting, measuring their gas permeability before and after the alcohol treatment as a means of tracking recovery of free volume. One of the most promising applications of PIM-1 membranes at commercial scale is the sweetening of natural gas. Therefore, the separation of the relevant gas pair $\mathrm{CO}_{2} / \mathrm{CH}_{4}$ was investigated.

\section{Experimental}

\subsection{Materials}

Potassium carbonate $\left(\mathrm{K}_{2} \mathrm{CO}_{3}\right)$ and 2,3,5,6-tetrafluoroterephthalonitrile (TFTPN) were purchased from SigmaAldrich (UK). 3,3,3',3'-Tetramethyl-1,1'-spirobisindane5,5',6,6'-tetraol (TTSBI) was purchased from Alfa Aesar (UK). Dimethylacetamide, dichloromethane, chloroform, toluene, acetone, methanol $(\geqslant 99.5 \%)$ and ethanol $(\geqslant 99.5 \%)$ were purchased from Sigma-Aldrich (UK).
TFTPN was purified by sublimation at $150{ }^{\circ} \mathrm{C}$ and then collected without vacuum. TTSBI was dissolved in methanol and precipitated in dichloromethane before use. All the other chemicals were used as received.

\subsection{Synthesis of PIM-1}

PIM-1 was synthetized following the procedure proposed by $\mathrm{Du}$ et al. [34]. Firstly, $10.00 \mathrm{~g}$ of TFTPN, $17.29 \mathrm{~g}$ of TTSBI and $20.73 \mathrm{~g}$ of $\mathrm{K}_{2} \mathrm{CO}_{3}$ were reacted in a mixed solvent of $100 \mathrm{~mL}$ of dimethylacetamide and $50 \mathrm{~mL}$ of toluene under $\mathrm{N}_{2}$ at $160{ }^{\circ} \mathrm{C}$. Reflux and constant mechanical stirring of the solution was set for $40 \mathrm{~min}$, after which a highly viscous solution was produced. This solution was soaked in methanol and left overnight. The yellow crude product was collected by vacuum filtration and washed three times with methanol and a final wash with acetone. Then, it was dissolved in chloroform and reprecipitated in methanol. The recovered product was refluxed for $12 \mathrm{~h}$ in water at $100{ }^{\circ} \mathrm{C}$ and then dried under vacuum at $110{ }^{\circ} \mathrm{C}$ overnight.

\subsection{Fabrication of membranes}

Thirteen freestanding PIM-1 membranes were prepared through a solvent evaporation method. First, the synthesized PIM-1 powder was dissolved in chloroform at a concentration of $4 \mathrm{wt}-\%$ under magnetic stirring for $24 \mathrm{~h}$. Then, the dope solution was cast on Steriplan ${ }^{\circledR}$ petri dishes (5 $\mathrm{cm}$ diameter) that were immediately covered and left in the fume cupboard for $3 \mathrm{~d}$ at room temperature. The thickness of the membranes was measured using a digital micrometer screw gauge with an accuracy of $\pm 0.5 \mu \mathrm{m}$ (Mitutoyo IP65 Coolant Proof, UK). At least five measurements were performed on each membrane to obtain an average thickness.

\subsection{Membrane treatment}

From the prepared PIM-1 membranes, three were tested without any alcohol treatment and were labelled as PIM-1 as-cast (Table 1). The rest were subjected to treatment with methanol or ethanol the day after collection from the petri dish (day 1). For the treatment, membranes were immersed in alcohol for $24 \mathrm{~h}$ at room temperature, and subsequently placed in a vacuum oven at $120^{\circ} \mathrm{C}$ for $10 \mathrm{~h}$ to remove any trapped residual solvents. Further treatment with alcohol vapor was carried out for two of the ethanol-treated membranes and two of the methanol-treated ones, using the same vaporized alcohol as that in the initial solvent treatment. PIM-1 membranes were placed in a membrane cell and exposed to the alcohol vapor generated by the heating of either ethanol or methanol at $50{ }^{\circ} \mathrm{C}$. A vacuum of 10 mbar was applied on the downstream side of the membrane in order to force the passage of the alcohol vapor across the membrane. This procedure is illustrated in 
Table $1 \quad \mathrm{CO}_{2}$ permeability and $\mathrm{CO}_{2} / \mathrm{CH}_{4}$ selectivity of fresh and aged PIM-1 membranes

\begin{tabular}{|c|c|c|c|c|}
\hline$\overline{\text { Membrane code }}$ & Aging time/d & $\mathrm{CO}_{2}$ Permeability/barrer & Selectivity $\left(\alpha_{\mathrm{CO}_{2} / \mathrm{CH}_{4}}\right)$ & Average thickness $/ \mu \mathrm{m}$ \\
\hline$\overline{\text { PIM-1 (as-cast) }}{ }^{\text {a) }}$ & 2 & $2755 \pm 137$ & $18.1 \pm 4.2$ & $(39 \pm 1)(35 \pm 3)(44 \pm 3)$ \\
\hline \multirow[t]{2}{*}{ PIM-1-MeOH-L(1) } & 1 & $6272 \pm 142$ & $12.1 \pm 1.0$ & $(34 \pm 2)(30 \pm 5)(36 \pm 3)$ \\
\hline & 26 & $3810 \pm 868$ & $18.1 \pm 4.0$ & $(41 \pm 2)(40 \pm 4)(43 \pm 4)$ \\
\hline \multirow[t]{2}{*}{ PIM-1-EtOH-L(1) ${ }^{\text {a) }}$} & 2 & $4513 \pm 1228$ & $19.1 \pm 1.4$ & $(48 \pm 4)(56 \pm 5)(53 \pm 3)$ \\
\hline & 27 & $3217 \pm 614$ & $22.6 \pm 2.7$ & $(53 \pm 6)(47 \pm 9)(51 \pm 8)$ \\
\hline \multirow[t]{5}{*}{ PIM-1-MeOH-L(1)-V(120)-a } & 4 & 6314 & 11.8 & $34 \pm 4$ \\
\hline & 26 & 4432 & 13.9 & \\
\hline & 92 & 3067 & 17.9 & \\
\hline & 118 & 2732 & 20.7 & \\
\hline & $121^{\text {b) }}$ & 7020 & 11.4 & \\
\hline \multirow[t]{3}{*}{ PIM-1-MeOH-L(1)-V(114)-b } & 4 & 6432 & 11.2 & $30 \pm 5$ \\
\hline & 92 & 3221 & 17.2 & \\
\hline & $115^{\mathrm{b})}$ & 7165 & 10.1 & \\
\hline \multirow[t]{4}{*}{ PIM-1-EtOH-L(1)-V(124)-a } & 14 & 5422 & 16.1 & $65 \pm 9$ \\
\hline & 73 & 3760 & 17.4 & \\
\hline & 101 & 3216 & 17 & \\
\hline & $125^{\mathrm{b})}$ & 4306 & 15.3 & \\
\hline \multirow[t]{4}{*}{ PIM-1-EtOH-L(1)-V(120)-b } & 26 & 3364 & 15.4 & $25 \pm 2$ \\
\hline & 92 & 1802 & 22.1 & \\
\hline & 119 & 1327 & 23.6 & \\
\hline & $121^{\text {b) }}$ & 3712 & 13.3 & \\
\hline
\end{tabular}

Note: a) Three different membranes were measured; permeability and selectivity are the average value for these 3 membranes and errors are the calculated standard deviation. The average thickness of each individual membrane is shown. b) These membranes were treated either with methanol or ethanol vapor for $8 \mathrm{~h}$ prior to analyzing their gas separation performance.
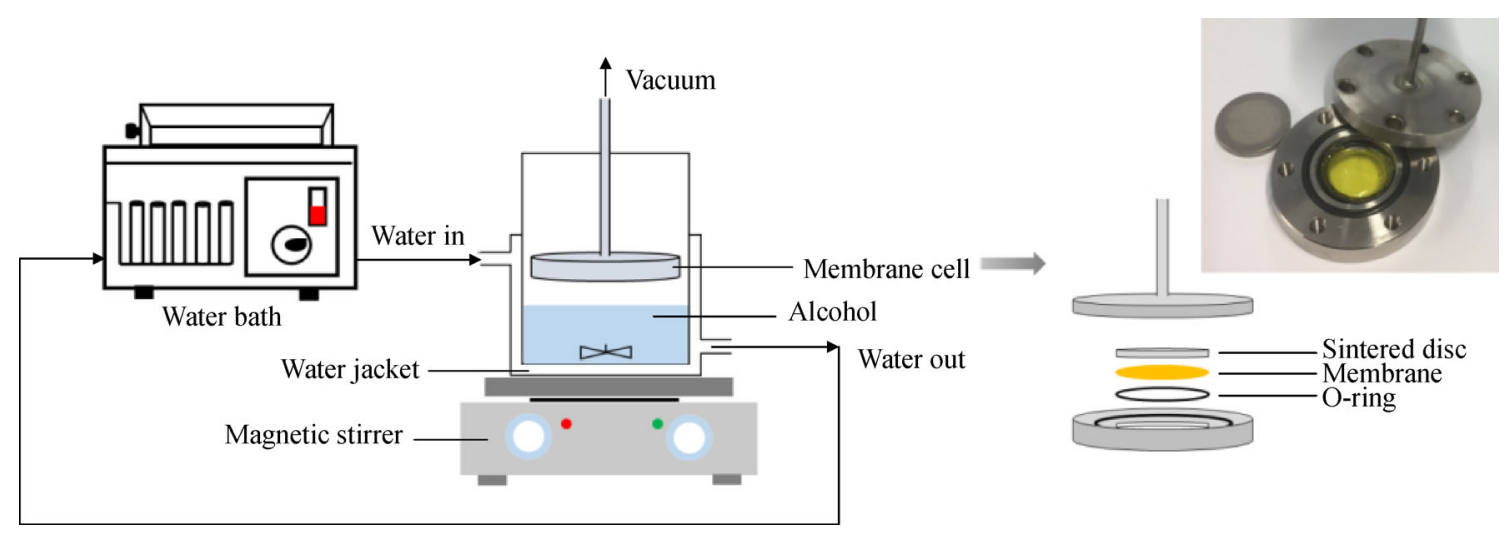

Fig. 1 Schematic of the apparatus used for the alcohol treatment of PIM-1 membranes (alcohol is kept at constant temperature by means of a water bath) and components of the membrane cell in more detail.

Fig. 1 with details on the membrane cell used. Table 1 displays the codes given to the membranes.

These membranes were treated either with liquid ethanol or liquid methanol the day after collection from casting petri dishes (day 1). Some of these membranes were further aged and some were treated with methanol or ethanol vapor after at least $114 \mathrm{~d}$ have passed. Aging time is the number of days after removal from petri dishes. As-cast PIM-1 membranes were also tested for comparison. The membranes were labelled using the following code: PIM1-(alcohol used in the treatment: $\mathrm{MeOH}$ or EtOH)-L(day of soaking in liquid alcohol)-V(day of vapor alcohol treatment)-a or $b$ to designate different membranes. For example membrane PIM-1-MeOH-L(1)-V(120)-a is a 
membrane first soaked in methanol at day 1 and treated with methanol vapor $119 \mathrm{~d}$ later.

\subsection{PIM-1 powder and membrane characterization}

Weight-average molecular weight $\left(M_{\mathrm{w}}\right)$, number-average molecular weight $\left(M_{\mathrm{n}}\right)$ and polydispersity index (PDI) of the PIM-1 polymer was determined by gel permeation chromatography (GPC). This analysis was carried out on a Viscotek GPC mac VE 2001 instrument using tetrahydrofuran as the eluent at a flow rate of $1 \mathrm{~mL} \cdot \mathrm{min}^{-1}$ and an injection volume of $100 \mu \mathrm{L}$ using Viscotek GPC VE2001 columns and Viscotek 3580 refractive index detector. Polystyrene standards were used for the calibration of the system.

The apparent surface area of PIM-1 was determined by Brunauer-Emmett-Teller (BET) analysis of the $\mathrm{N}_{2}$ adsorption isotherm at $77 \mathrm{~K}$. For that, PIM-1 powder was exposed to nitrogen at $77 \mathrm{~K}$ using a Micromeritics ASAP 2020 volumetric adsorption analyser (Micromeritics, USA). PIM-1 sample was first degassed under high vacuum at $60{ }^{\circ} \mathrm{C}$ for $12 \mathrm{~h}$.

Thermogravimetric Analysis (TGA) was conducted to study the thermal stability of the PIM-1 polymer powder and the prepared films. A TGA 550 thermal analyser (TA instruments, USA) was used, heating from room temperature to $800{ }^{\circ} \mathrm{C}$ at a rate of $10{ }^{\circ} \mathrm{C} \cdot \mathrm{min}^{-1}$.

The morphology of the freestanding PIM-1 membranes was studied by scanning electron microscopy (SEM) using a FEI Quanta 200 microscope (FEI, USA). The cross sectional samples were prepared via cryo-fracturing in liquid nitrogen. The samples were sputtered with Platinum nanoparticles using an Emitech sputter coater (Quorom Technologies, UK) before imaging.

The chemical structure of PIM-1 was qualitatively studied using attenuated total reflection Fourier transform infrared spectroscopy (FTIR). The spectra were acquired with an iDS Nicolet iS5 instrument (Thermo Scientific, UK), equipped with a Ge crystal over the wavenumber range of $600-4000 \mathrm{~cm}^{-1}$ and step size of $0.5 \mathrm{~cm}^{-1}$.

(a)

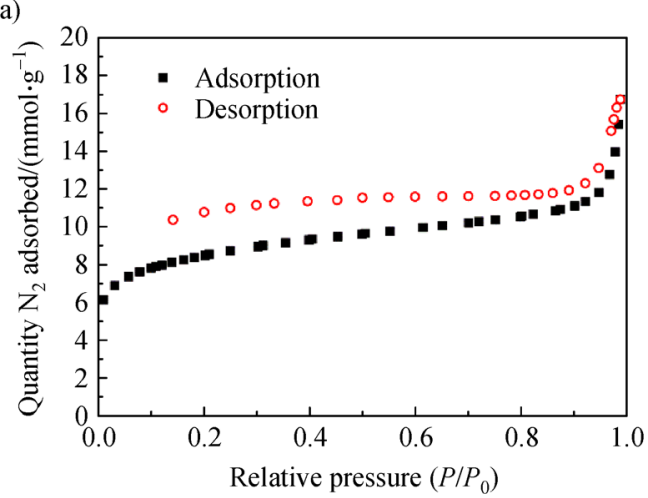

\subsection{Gas permeation measurements}

Gas permeation measurements were performed for $\mathrm{CO}_{2} / \mathrm{CH}_{4}$ binary mixture $(1: 1, \mathrm{v}: \mathrm{v})$ with a flow rate of $25 \mathrm{~mL} \cdot \mathrm{min}^{-1}$ of each gas. The feed solution was pressurized at 3 bar, while the permeate side was kept at atmospheric pressure. Helium (flow rate of $20 \mathrm{~mL} \cdot \mathrm{min}^{-1}$ ) was used as a sweep gas to dilute the permeating gases and direct them to a gas chromatography system (490 micro GC, Agilent, USA) equipped with a PoraPLOT (PPU) column for the analysis of the permeate composition. The experiments were conducted at $25{ }^{\circ} \mathrm{C}$. The gas permeability for each gas $\left(P_{\mathrm{i}}\right)$ was calculated using Eq. (1):

$$
P_{i}=\frac{Q_{i} l}{A \Delta p},
$$

where $i$ is either $\mathrm{CO}_{2}$ or $\mathrm{CH}_{4}, Q_{i}$ is the permeate flow of gas $i\left(\mathrm{~cm}^{3}(\mathrm{STP}) \cdot \mathrm{s}^{-1}\right), l$ is the membrane thickness $(\mathrm{cm}), A$ is the effective membrane area $\left(\mathrm{cm}^{2}\right)$ and $\Delta p$ is a the partial pressure difference across the membrane $(\mathrm{cmHg})$ for gas component $i$. The results are given in barrer units (1 barrer $\left.=10^{-10} \cdot \mathrm{cm}^{3}[\mathrm{STP}] \cdot \mathrm{cm} \cdot \mathrm{cm}^{-2} \cdot \mathrm{s}^{-1} \cdot \mathrm{cmHg}^{-1}\right)$. The selectivity for the gas pair is calculated as the ratio of the permeabilities of the most permeable gas $\left(P_{\mathrm{CO}_{2}}\right)$ over the less permeable gas $\left(P_{\mathrm{CH}_{4}}\right)$, as shown in Eq. (2):

$$
\alpha_{\mathrm{CO}_{2} / \mathrm{CH}_{4}}=\frac{P_{\mathrm{CO}_{2}}}{P_{\mathrm{CH}_{4}}} \text {. }
$$

\section{Results and discussion}

\subsection{PIM-1 and membrane characterization}

The $M_{\mathrm{w}}, M_{\mathrm{n}}$ and PDI of the PIM-1 synthesized in this study are $118800 \mathrm{~g} \cdot \mathrm{mol}^{-1}, 32900 \mathrm{~g} \cdot \mathrm{mol}^{-1}$ and 3.6 , respectively. Figure 2(a) shows the $\mathrm{N}_{2}$ adsorption/desorption isotherms of PIM-1 powder at $77 \mathrm{~K}$. It can be observed that PIM-1 shows high $\mathrm{N}_{2}$ uptake at very low relative pressures. The

(b)

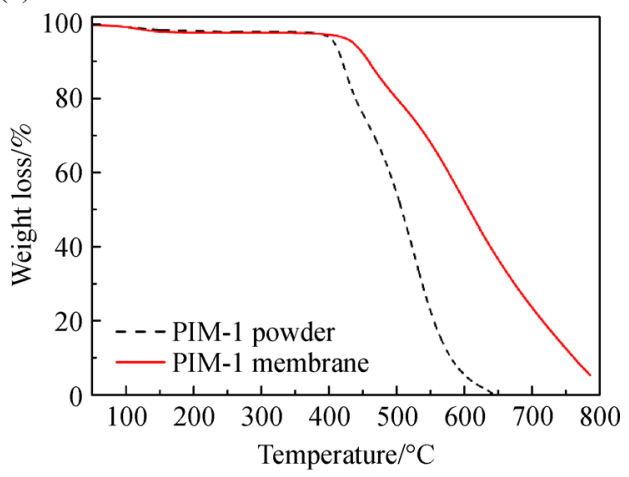

Fig. 2 (a) $\mathrm{N}_{2}$ adsorption/desorption at $77 \mathrm{~K}$ for PIM-1 (square and circle symbols represent the adsorption and desorption data, respectively), and (b) TGA curves of PIM-1 powder and a PIM-1 membrane that has undergone methanol-vapor treatment. 
BET surface area of PIM-1 is $657 \pm 8 \mathrm{~m}^{2} \cdot \mathrm{g}^{-1}$, which is in the typical range of values reported for PIM-1 in the literature. The thermal stability of PIM-1 powder and freestanding PIM-1 membranes was investigated through TGA. Thermogravimetric curves are shown in Fig. 2(b). It can be observed that both samples present similar thermal behavior. Below $120{ }^{\circ} \mathrm{C}$ any weight loss was due to the removal of residual solvents that might be weakly adsorbed by the material [35]. Both PIM-1 powder and PIM-1-freestanding membranes are thermally stable up to $450{ }^{\circ} \mathrm{C}$, as the mass loss is not significant up to that temperature.

The surface and cross-section of a liquid-ethanol treated PIM-1 membrane before aging (PIM-1-EtOH-L(1)-V (120)-b), are shown in micrographs a and c in Fig. 3, respectively, and confirm the preparation of defect-free dense membranes. In addition, the cross section of an ascast PIM-1 membrane is shown in Fig. 3(b). Some elongated deformations are present in both cross sections, with more intense creases for the as-cast membrane; these features can typically arise from the "freeze-fracture" process during sample preparation and do not indicate the presence of defects or voids within the dense membrane structure, as suggested by the gas separation performance discussed in section 3.2. The amount of residual solvent within the polymer matrix, after solvent evaporation at ambient conditions or even after vacuum treatment, influences the quality of the prepared samples; the presence of trapped solvent can lead to a more effective freezing of the polymer membrane and therefore, samples with less artificial topology, as observed in Fig. 3(c). The thickness measured for the membranes via SEM is in accordance with that measured with the micrometer.

The FTIR spectrum of an as-cast PIM-1 membrane is shown in Fig. 4 and it contains the characteristic bands and peaks that have been previously reported in the literature: aliphatic and aromatic $\mathrm{C}-\mathrm{H}$ stretching (ca. 2800-3010 $\left.\mathrm{cm}^{-1}\right)$, nitrile groups $\left(\mathrm{C} \equiv \mathrm{N}, \mathrm{ca} .2240 \mathrm{~cm}^{-1}\right), \mathrm{C}=\mathrm{C}$ aromatic bending (ca. $1607 \mathrm{~cm}^{-1}$ ) and $\mathrm{C}-\mathrm{O}$ stretching (ca. 1000$\left.1300 \mathrm{~cm}^{-1}\right)[35,36]$.
3.2 Evaluation of aging in PIM-1 membranes via gas permeation

Soaking membranes in polar solvents such as ethanol and methanol is often used to remove any trapped solvent or contaminants within the PIM-1 microstructure, and also to reverse the effects of aging of the films. When alcohols penetrate PIM-1 they induce swelling, polymer chains relax and this allows residual solvent to be flushed out [13]. After the removal and evaporation of the alcohol, films present an enhancement of gas permeability due to the increase of free volume. In this regard, the gas separation performance was studied for $\mathrm{CO}_{2} / \mathrm{CH}_{4}$ mixtures of untreated (as-cast) PIM-1 membranes, and methanol- and ethanol-treated membranes (fresh and aged ones). The $\mathrm{CO}_{2}$ permeabilities and $\mathrm{CO}_{2} / \mathrm{CH}_{4}$ selectivities obtained for all the membranes are shown in Table 1 and plotted in permeability and selectivity graphs in Fig. 5. Untreated fresh PIM-1 membranes showed the lowest average $\mathrm{CO}_{2}$ permeability ( $2755 \pm 137$ barrer) due to the blockage of the pores by residual casting solvent still present in the microstructure of the membranes, as has previously been reported in the literature $[13,37]$. When soaked in lower alcohols, the average $\mathrm{CO}_{2}$ permeability of fresh PIM-1 membranes increased, more when methanol was used $(6272 \pm 142$ and $4513 \pm 1228$ barrer for methanol and ethanol, respectively). As expected, at day 27 (ca. 4 weeks after casting), the $\mathrm{CO}_{2}$ permeability of methanol and ethanol-treated membranes dropped by $39.3 \%$ and $29.7 \%$, respectively. This behavior has been previously reported in the literature $[21,38]$ and confirms the tendency to lose free volume within the polymer structure (i.e., physical aging). It is worth noting that in a previous paper from our group a very similar $\mathrm{CO}_{2}$ permeability loss was reported, $35.9 \%$ at day 35 for freestanding PIM-1 membranes initially soaked in liquid methanol [21].

As can be observed in Table 1, liquid methanol-treated PIM-1 membrane showed higher overall $\mathrm{CO}_{2}$ permeability right after the alcohol treatment, and also ca. 4 weeks later, as compared to ethanol-treated PIM-1 membranes. As a

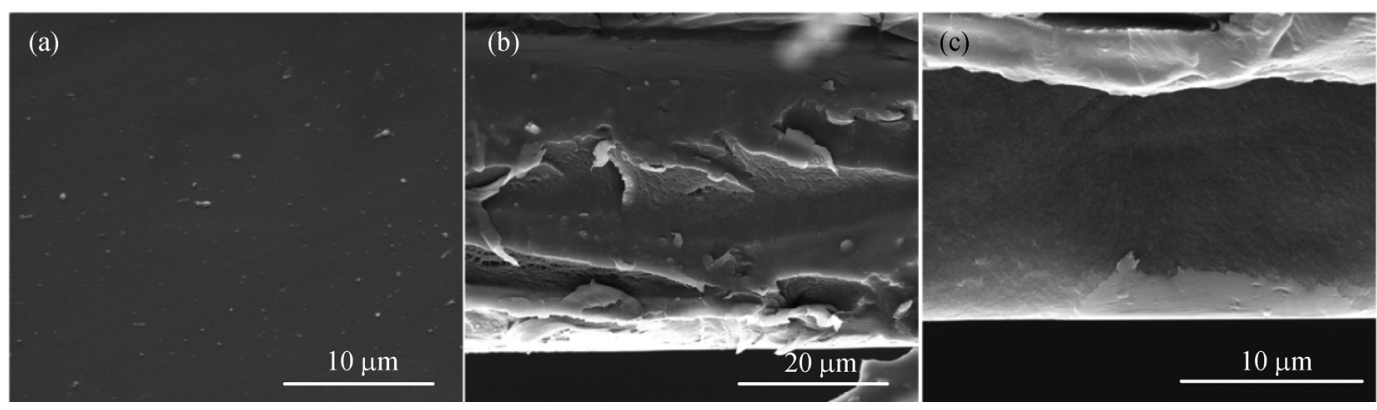

Fig. 3 SEM images of (a) the surface of an ethanol-treated PIM-1 membrane, (b) cross-section of as-cast PIM-1 membrane, and (c) cross-section of ethanol-treated membrane (PIM-1-EtOH-L(1)-V(120)-b). 


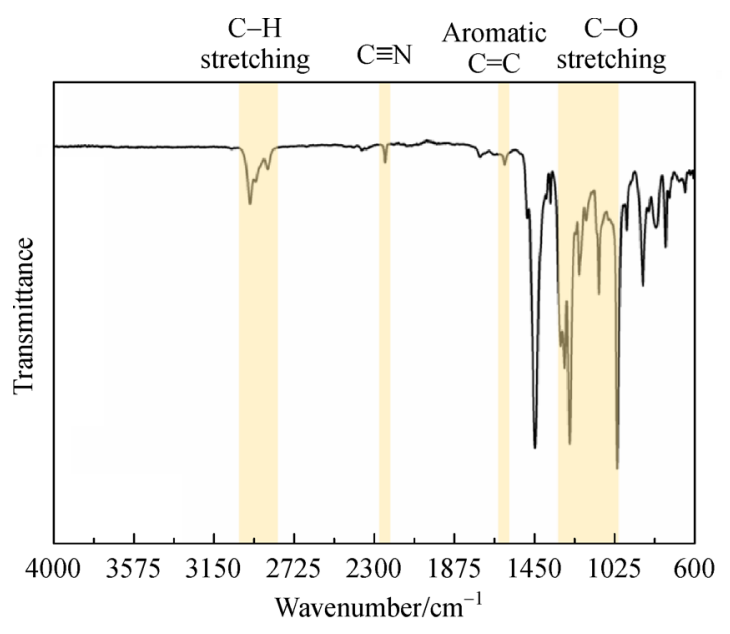

Fig. 4 FTIR spectrum of an as-cast PIM-1 freestanding membrane.

consequence of physical aging, the average $\mathrm{CO}_{2}$ permeability dropped from $6272 \pm 142$ barrer down to $3810 \pm$ 868 barrer in just $26 \mathrm{~d}$, and the $\mathrm{CO}_{2} / \mathrm{CH}_{4}$ selectivity increased to $18.1 \pm 4.0$. These results show a superior overall performance of methanol-treated membranes compared to ethanol-treated ones, as more free volume was created upon methanol treatment. This was also observed by Mason et al. [6]. In that study, methanolsoaked aged PIM-1 films showed not only a full recovery of their gas permeabilities but also an increase compared to ethanol-treated PIM-1 films. McDermott et al. studied the effect of ethanol and methanol treatment of aged PIM-1 films on their small-angle X-ray scattering and wide-angle X-ray scattering patterns [25]. Since the porosity in PIMs, which is correlated to free volume, affects the scattering patterns, these patterns can be used to study the physical aging. Larger absolute intensity corresponds with larger porosity and, consequently, larger free volume. Their findings showed that methanol-treated PIM-1 films have larger scattering intensity compared to ethanol-treated ones, which in turn is associated with higher porosity and therefore correlated to free volume. This suggests that methanol use might be more effective as a rejuvenating procedure [25]. The effectiveness of methanol treatment in reversing the physical aging effects can also be related to the higher vapor pressure of methanol $\left(16.96 \mathrm{kPa}\right.$ at $\left.25^{\circ} \mathrm{C}\right)$ compared with ethanol $\left(7.85 \mathrm{kPa}\right.$ at $\left.25^{\circ} \mathrm{C}\right)$. The higher the vapor pressure, the stronger the driving force for the alcohol to evacuate the polymer structure once it is removed from the liquid, leaving additional free volume in the PIM-1. The rate of evaporation is related to the time needed for the chains to rearrange themselves in the matrix. Therefore, the higher the evaporation rate, the less time the chains have to reorient which causes an increase in free volume [11].

Vapor solvent treatment has been previously reported to enhance the mechanical properties and separation performance of electrospun membranes $[39,40]$. However, to the best of our knowledge, this is the first study that addresses the use of vapor solvent to reverse the effect of physical aging. $\mathrm{CO}_{2}$ and $\mathrm{CH}_{4}$ gas permeabilities and $\mathrm{CO}_{2} / \mathrm{CH}_{4}$ selectivity of methanol and ethanol vapor-treated membranes were monitored as a function of time. The values obtained are shown in Table 1 and also displayed in Fig. 5. It can be observed that all aged PIM-1 membranes show a decrease in gas permeability and increase in selectivity over time, similar to what is reported in other studies $[9,21]$. As previously explained, this is due to the loss of excess free volume and consequent rearrangement and packing of the polymer chains, and follows the trade-off between permeability and selectivity commonly seen in polymeric membranes [41]. According to Bernardo et al. [42], the effect of physical aging on the permeability, $P$, of aged PIM-1 membranes can be described by Eq. (3):

$$
P=P_{0} t^{-\beta_{\mathrm{p}}} \text { or } \log P=\log P_{0}-\beta_{P} \log t
$$

where $P_{0}$ is the initial permeability at $t=1$ and $\beta_{\mathrm{p}}$ is the permeability aging rate constant. Figure 6 displays $\beta_{\mathrm{p}}$ values for PIM-1 membranes aged for ca. 4 months (last four membranes in Table 1: PIM-1-MeOH-L(1)-V(120)-a, PIM-1-MeOH-L(1)-V(114)-b, PIM-1-EtOH-L(1)-V(124)$a$ and PIM-1-EtOH-L(1)-V(120)-b) as a function of the square of the effective diameter $\left(d_{\text {eff }}\right)$ of permeating gases $\mathrm{CO}_{2}$ and $\mathrm{CH}_{4}$ in $\mathrm{nm}^{2} . \beta_{\mathrm{p}}$ values are very similar to those reported for PIM-1 membranes by Bernardo et al. [42] and Scholes \& Kanehashi [43], which are also plotted in Fig. 6 for $\mathrm{CO}_{2}, \mathrm{CH}_{4}$ along with other gases. Only membrane PIM-1-EtOH-L(1)-V(120)-b shows higher $\beta_{\mathrm{p}}$ values, possibly due to the lower extent of opening up free volume with the initial ethanol soaking; it is worth noting that this membrane shows the lowest initial gas permeability of all, which upon aging for $120 \mathrm{~d}$, falls below 2000 barrer.

When exposed to alcohol vapor ca. 4 months after casting, aged PIM-1 membrane PIM-1-MeOH-L(1)-V (120)-a and PIM-1-MeOH-L(1)-V(114)-b showed a full recovery of their $\mathrm{CO}_{2}$ permeability, with values of 7020 and 7165 barrer, respectively, which are slightly above those reported initially right after the liquid-methanol treatment. On the other hand, membranes PIM-1-EtOH-L (1)-V(124)-a and PIM-1-EtOH-L(1)-V(120)-b, which were initially treated with liquid ethanol and aged for about the same period of time, also recovered their initial $\mathrm{CO}_{2}$ permeability but the values were more scattered and ca. 50\% lower. These results are again in accordance with the literature that reports the higher effectiveness of using methanol for making free volume of PIM-1 more accessible [6]. The fact that the permeability of methanol through freestanding PIM-1 membranes is approximately 3 -fold the permeability of ethanol [44], also suggest a more effective treatment when the one-carbon solvent is used.

Figure 7 shows the behavior of the methanol-treated membranes PIM-1-MeOH-L(1)-V(120)-a and PIM-1- 

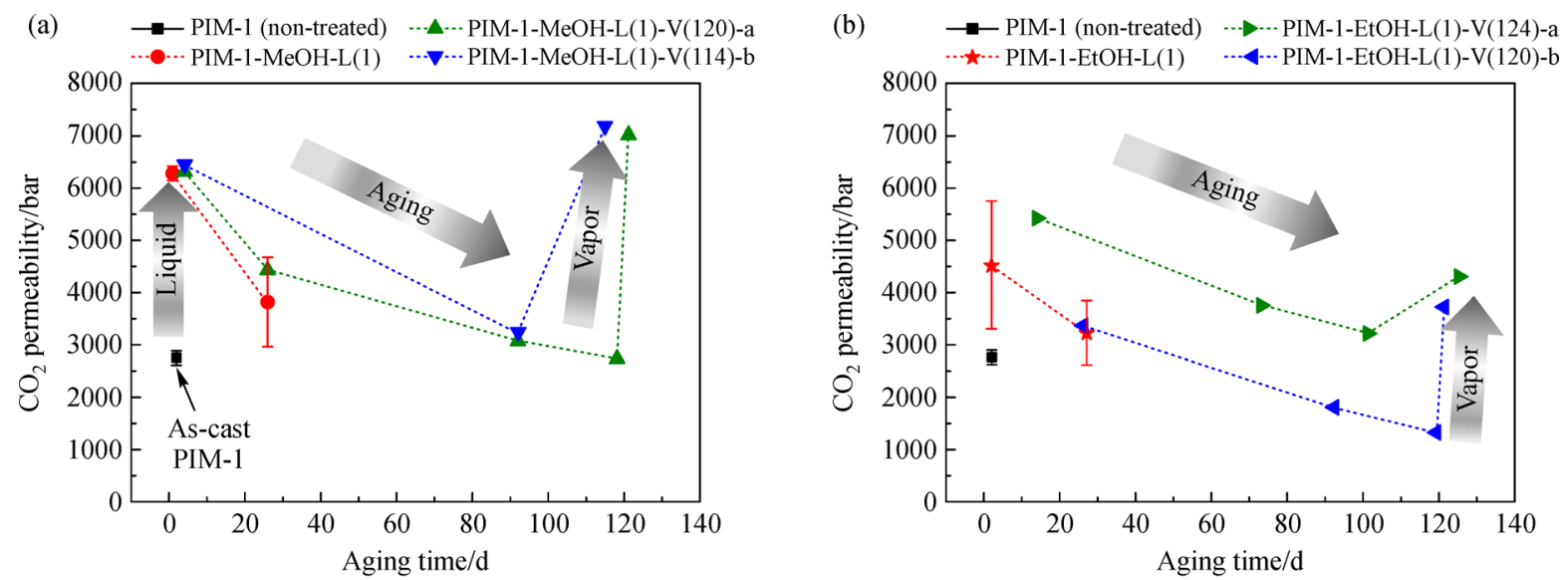

(c) $\quad \rightarrow-$ PIM-1 (non-treated) $\quad \cdots \Delta \cdots$ PIM-1-MeOH-L(1)-V(120)-a

(d) $\quad \rightarrow-$ PIM-1 (non-treated) $\quad \cdots \cdots$ PIM-1-EtOH-L(1)-V(124)-a
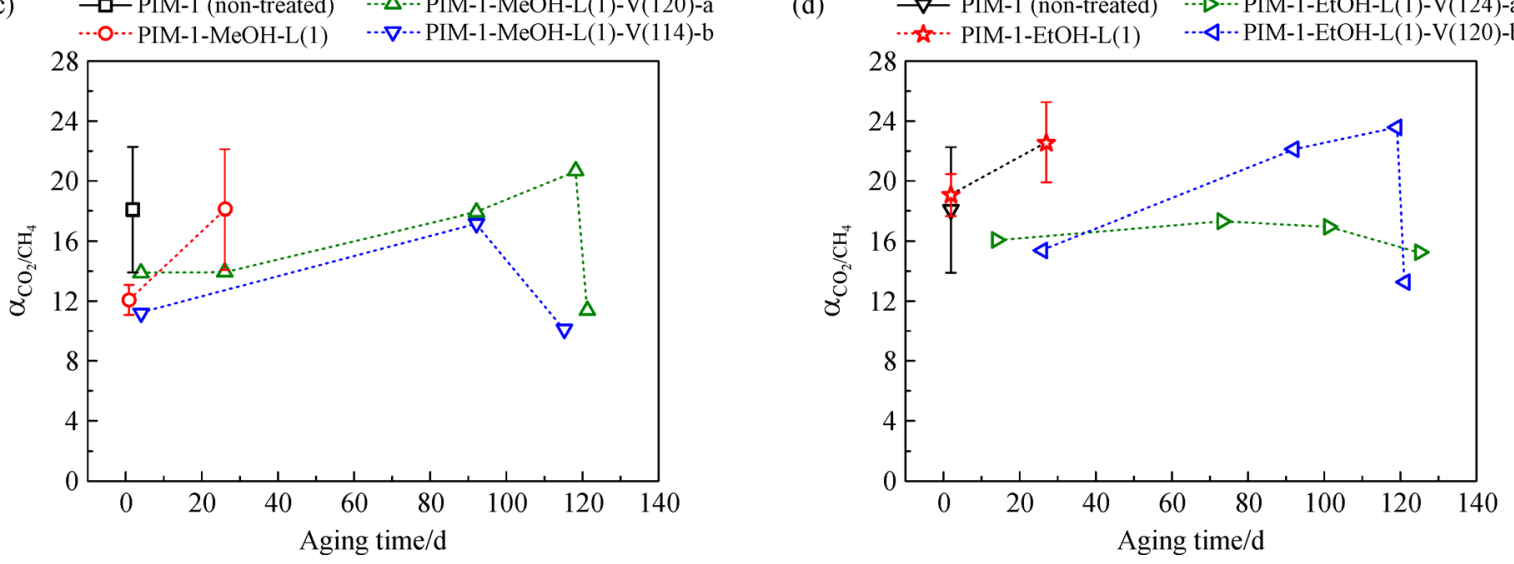

Fig. $5 \mathrm{CO}_{2}$ permeability of freestanding PIM-1 membranes treated with (a) methanol and (b) ethanol vapor, and $\mathrm{CO}_{2} / \mathrm{CH}_{4} \mathrm{selectivity} \mathrm{for}$ the same membranes treated with (c) methanol and (d) ethanol vapor. Membranes were tested using a $\mathrm{CO}_{2} / \mathrm{CH}_{4}$ binary mixture (1:1, v:v) as feed at $25{ }^{\circ} \mathrm{C}$ under a transmembrane pressure of approximately 2 bar. Values are the average permeability and selectivity for 3 membranes for those showing error bars and errors are the calculated standard deviation. PIM-1 membranes were initially treated by soaking in liquid ethanol or liquid methanol and their $\mathrm{CO}_{2} / \mathrm{CH}_{4}$ separation performance was determined at different intervals up to ca. 120 d. The membranes represented by triangles in the plot were last treated with alcohol vapor (methanol or ethanol) after ca. 4 months; the last data points give their $\mathrm{CO}_{2}$ permeability and selectivity at that stage. All the other points in between refer to an aged state of the membrane. Filled symbols are used for $\mathrm{CO}_{2}$ permeability values and open symbols are used for $\mathrm{CO}_{2} / \mathrm{CH}_{4}$ selectivity. Squares $(\boldsymbol{\square}, \square)$ correspond to PIM-1 as-cast, circles $(\mathbf{O}, \bigcirc)$ correspond to PIM-1 membranes soaked in liquid methanol, stars $(\star, \star \succsim)$ correspond to a PIM-1 membranes

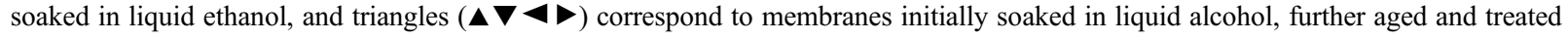
with vapor methanol or vapor ethanol after at least $114 \mathrm{~d}$ have passed.

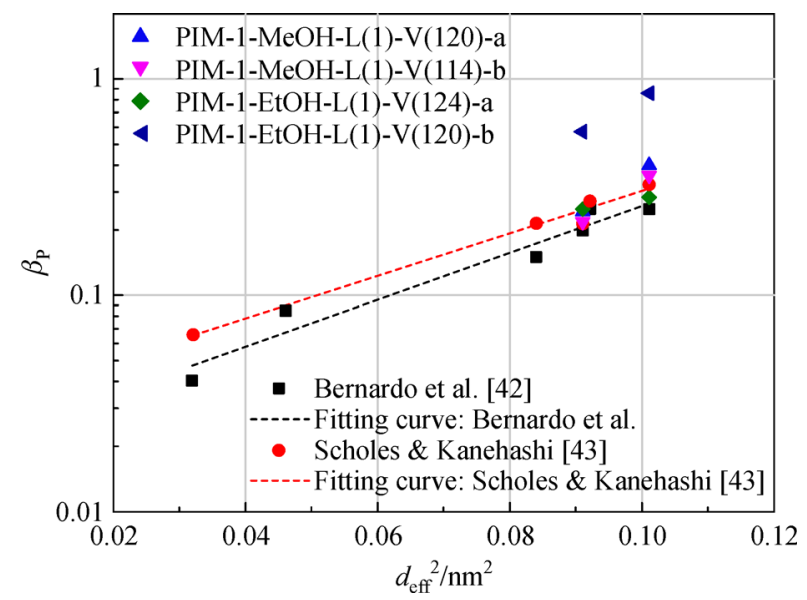

Fig. 6 Aging rate constant $\left(\beta_{\mathrm{P}}\right)$ as a function of the square of the effective gas diameter for PIM-1 membranes. 


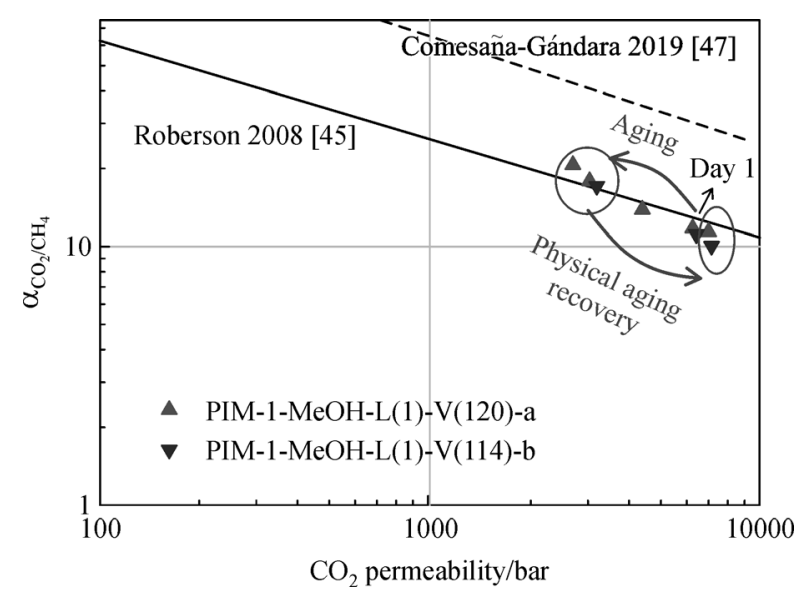

Fig. 7 Robeson plot displaying the aging behavior of PIM-1 membranes PIM-1-MeOH-L(1)-V(120)-a and PIM-1-MeOH-L (1)-V(114)-b, which were initially treated by soaking in methanol, aged for ca. 4 months (120 and $114 \mathrm{~d}$, respectively) and subsequently treated with methanol vapor, for the separation of $\mathrm{CO}_{2} / \mathrm{CH}_{4}(1: 1, \mathrm{v}: \mathrm{v})$ mixtures. Testing was done at $25{ }^{\circ} \mathrm{C}$ and approximately 2 bar transmembrane pressure. The solid line corresponds to the revisited 2008 Robeson upper bound [45] and the dotted line represents the proposed 2019 upper bound [47]. The arrows show the aging process over the tested period and they point towards the most aged membranes.

MeOH-L(1)-V(114)-b on a $\mathrm{CO}_{2} / \mathrm{CH}_{4}$ selectivity vs $\mathrm{CO}_{2}$ permeability double logarithmic plot. As anticipated, all PIM-1 membranes lie along the 2008 upper bound [45], since it was one of the polymers Robeson used to revisit the previous upper bound from 1991 [46]. As membranes age over time the data points move towards lower $\mathrm{CO}_{2}$ permeability and higher $\mathrm{CO}_{2} / \mathrm{CH}_{4}$ selectivity, following the 2008 trade-off upper bound. At days 114 and 120, membranes PIM-1-MeOH-L(1)-V(120)-a and PIM-1$\mathrm{MeOH}-\mathrm{L}(1)-\mathrm{V}(114)-\mathrm{b}$ were exposed to methanol vapor for $8 \mathrm{~h}$, respectively, and gas performance evaluated the following day. The initial performance was recovered in both cases, with $\mathrm{CO}_{2}$ permeability values in the 7000 barrer range and $\mathrm{CO}_{2} / \mathrm{CH}_{4}$ selectivity around 11 .

\section{Conclusions}

This study shows an effective procedure to reverse the effect of physical aging on PIM-1 membranes by exposure to vaporized alcohols (methanol or ethanol). It is anticipated that this could be done in situ at large scale gas separation plants. While the results obtained in this study are promising, more membranes need to be tested under different conditions, especially at higher feed pressures and at gas compositions closer to those of natural gas, in order to have a deeper and better understanding of the reversal of the physical aging effects under real operating conditions. Also, it would be useful to explore if reversibility of physical aging by means of alcohol vapor treatment would only be required upon installation of the membrane modules and after plants shutdowns; a contrasting effect of aging, i.e., plasticization, which typically occurs in glassy polymer membranes due to the presence of $\mathrm{CO}_{2}$ at high pressures of a few tens of bar (typical operation conditions of sweetening of natural gas), most likely will impede physical aging during membrane operation.

These findings suggest the effectiveness of the vapor methanol treatment as a 'rejuvenation' process which may bring the use of PIM-1 membranes in industrial applications one step closer.

Acknowledgements Faiz Almansour is grateful to the Department of Research \& Development, Saudi Aramco for funding and supporting his $\mathrm{Ph}$.D. studies. M. Alberto is grateful to EPSRC for funding under the research grant number EP/S032258/1 and R. Bhavsar to EPSRC under grant number EP/M001342/1.

Open Access This article is licensed under a Creative Commons Attribution 4.0 International License, which permits use, sharing, adaptation, distribution and reproduction in any medium or format, as long as you give appropriate credit to the original author(s) and the source, provide a link to the Creative Commons licence, and indicate if changes were made. The images or other third party material in this article are included in the article's Creative Commons licence, unless indicated otherwise in a credit line to the material. If material is not included in the article's Creative Commons licence and your intended use is not permitted by statutory regulation or exceeds the permitted use, you will need to obtain permission directly from the copyright holder. To view a copy of this licence, visit http://creativecommons.org/licenses/by/4.0/.

\section{References}

1. Low Z X, Budd P M, McKeown N B, Patterson D A. Gas permeation properties, physical aging, and its mitigation in high free volume glassy polymers. Chemical Reviews, 2018, 118(12): 58715911

2. Budd P M, Ghanem B S, Makhseed S, McKeown N B, Msayib K J, Tattershall C E. Polymers of intrinsic microporosity (PIMs): robust, solution-processable, organic nanoporous materials. Chemical Communications, 2004, (2): 230-231

3. Budd P M, McKeown N B, Fritsch D. Polymers of intrinsic microporosity (PIMs): high free volume polymers for membrane applications. Macromolecular Symposia, 2006, 245-246(1): 403405

4. Kim S, Lee Y M. Rigid and microporous polymers for gas separation membranes. Progress in Polymer Science, 2015, 43: 1-32

5. Du N, Cin M M D, Pinnau I, Nicalek A, Robertson G P, Guiver M D. Azide-based cross-linking of polymers of intrinsic microporosity (PIMs) for condensable gas separation. Macromolecular Rapid Communications, 2011, 32(8): 631-636

6. Mason C R, Maynard-Atem L, Heard K W J, Satilmis B, Budd P M, Friess K, Lanc MBernardo P, Clarizia G, Jansen J C. Enhancement of $\mathrm{CO}_{2}$ affinity in a polymer of intrinsic microporosity by amine modification. Macromolecules, 2014, 47(3): 1021-1029

7. Bakhtin D S, Kulikov L A, Legkov S A, Khotimskiy V S, Levin I S, 
Borisov I L, Maksimov A L, Volkov V V, Karakhanov E A, Volkov A V. Aging of thin-film composite membranes based on PTMSP loaded with porous aromatic frameworks. Journal of Membrane Science, 2018, 554: 211-220

8. Harms S, Rätzke K, Faupel F, Chaukura N, Budd P M, Egger W, Ravelli L. Aging and free volume in a polymer of intrinsic microporosity (PIM-1). Journal of Adhesion, 2012, 88(7): 608-619

9. Tiwari R R, Jin J, Freeman B D, Paul D R. Physical aging, $\mathrm{CO}_{2}$ sorption and plasticization in thin films of polymer with intrinsic microporosity (PIM-1). Journal of Membrane Science, 2017, 537: 362-371

10. Nagai K, Nakagawa T. Effects of aging on the gas permeability and solubility in poly(1-trimethylsilyl-1-propyne) membranes synthesized with various catalysts. Journal of Membrane Science, 1995, 105(3): 261-272

11. Jue M L, McKay C S, McCool B A, Finn M G, Lively R P. Effect of nonsolvent treatments on the microstructure of PIM-1. Macromolecules, 2015, 48(16): 5780-5790

12. Swaidan R, Ghanem B, Litwiller E, Pinnau I. Physical aging, plasticization and their effects on gas permeation in "rigid" polymers of intrinsic microporosity. Macromolecules, 2015, 48 (18): 6553-6561

13. Budd P M, McKeown N B, Ghanem B S, Msayib K J, Fritsch D, Starannikova L, Belov N, Sanfirova O, Yampolskii Y, Shantarovich $\mathrm{V}$. Gas permeation parameters and other physicochemical properties of a polymer of intrinsic microporosity: polybenzodioxane PIM-1. Journal of Membrane Science, 2008, 325(2): 851-860

14. Bushell A F, Attfield M P, Mason C R, Budd P M, Yampolskii Y, Starannikova L, Rebrov A, Bazzarelli F, Bernardo P, Carolus Jansen J, Lanč M, Friess K, Shantarovich V, Gustov V, Isaeva V. Gas permeation parameters of mixed matrix membranes based on the polymer of intrinsic microporosity PIM-1 and the zeolitic imidazolate framework ZIF-8. Journal of Membrane Science, 2013, 427: 48-62

15. Carta M, Malpass-Evans R, Croad M, Rogan Y, Jansen J C, Bernardo P, Bazzarelli F, McKeown N B. An efficient polymer molecular sieve for membrane gas separations. Science, 2013, 339 (6117): 303-307

16. Carta M, Croad M, Malpass-Evans R, Jansen J C, Bernardo P, Clarizia G, Friess K, Lanč M, McKeown N B. Triptycene induced enhancement of membrane gas selectivity for microporous Tröger's base polymers. Advanced Materials, 2014, 26(21): 3526-3531

17. Rose I, Carta M, Malpass-Evans R, Ferrari M C, Bernardo P, Clarizia G, Jansen J C, McKeown N B. Highly permeable benzotriptycene-based polymer of intrinsic microporosity. ACS Macro Letters, 2015, 4(9): 912-915

18. Ma X, Mukaddam M, Pinnau I. Bifunctionalized intrinsically microporous polyimides with simultaneously enhanced gas permeability and selectivity. Macromolecular Rapid Communications, 2016, 37(11): 900-904

19. Song Q, Cao S, Pritchard R H, Ghalei B, Al-Muhtaseb S A, Terentjev E M, Cheetham A K, Sivaniah E. Controlled thermal oxidative crosslinking of polymers of intrinsic microporosity towards tunable molecular sieve membranes. Nature Communications, 2014, 5(1): 4813

20. Li F Y, Chung T S. Physical aging, high temperature and water vapor permeation studies of UV-rearranged PIM-1 membranes for advanced hydrogen purification and production. International Journal of Hydrogen Energy, 2013, 38(23): 9786-9793

21. Alberto M, Bhavsar R, Luque-Alled J M, Vijayaraghavan A, Budd P $\mathrm{M}$, Gorgojo P. Impeded physical aging in PIM-1 membranes containing graphene-like fillers. Journal of Membrane Science, 2018, 563: 513-520

22. Bhavsar R S, Mitra T, Adams D J, Cooper A I, Budd P M. Ultrahigh-permeance PIM-1 based thin film nanocomposite membranes on PAN supports for $\mathrm{CO}_{2}$ separation. Journal of Membrane Science, 2018, 564: 878-886

23. Yong W F, Kwek K H A, Liao K S, Chung T S. Suppression of aging and plasticization in highly permeable polymers. Polymer, 2015, 77: 377-386

24. Horn N R, Paul D R. Carbon dioxide plasticization of thin glassy polymer films. Polymer, 2011, 52(24): 5587-5594

25. McDermott A G, Budd P M, McKeown N B, Colina C M, Runt J. Physical aging of polymers of intrinsic microporosity: a SAXS/ WAXS study. Journal of Materials Chemistry. A, Materials for Energy and Sustainability, 2014, 2(30): 11742-11752

26. Hill A J, Pas S J, Bastow T J, Burgar M I, Nagai K, Toy L G, Freeman B D. Influence of methanol conditioning and physical aging on carbon spin-lattice relaxation times of poly(1-trimethylsilyl-1-propyne). Journal of Membrane Science, 2004, 243(1): 37-44

27. Razali M, Didaskalou C, Kim J F, Babaei M, Drioli E, Lee Y M, Szekely G. Exploring and exploiting the effect of solvent treatment in membrane separations. ACS Applied Materials \& Interfaces, 2017, 9(12): 11279-11289

28. Jimenez Solomon M F, Bhole Y, Livingston A G. High flux hydrophobic membranes for organic solvent nanofiltration (OSN)interfacial polymerization, surface modification and solvent activation. Journal of Membrane Science, 2013, 434: 193-203

29. Gorgojo P, Jimenez-Solomon M F, Livingston A G. Polyamide thin film composite membranes on cross-linked polyimide supports: improvement of RO performance via activating solvent. Desalination, 2014, 344: 181-188

30. Zhao Y, Yuan Q. Effect of membrane pretreatment on performance of solvent resistant nanofiltration membranes in methanol solutions. Journal of Membrane Science, 2006, 280(1): 195-201

31. Shukla R, Cheryan M. Performance of ultrafiltration membranes in ethanol-water solutions: effect of membrane conditioning. Journal of Membrane Science, 2002, 198(1): 75-85

32. Penha F M, Rezzadori K, Proner M C, Zanatta V, Zin G, Tondo D W, Vladimir de Oliveira J, Petrus J C C, Di Luccio M. Influence of different solvent and time of pre-treatment on commercial polymeric ultrafiltration membranes applied to non-aqueous solvent permeation. European Polymer Journal, 2015, 66: 492-501

33. Nguyen Q T, Favre E, Ping Z H, Néel J. Clustering of solvents in membranes and its influence on membrane transport properties. Journal of Membrane Science, 1996, 113(1): 137-150

34. Du N, Song J, Robertson G P, Pinnau I, Guiver M D. Linear high molecular weight ladder polymer via fast polycondensation of 5,5',6,6'-tetrahydroxy-3,3,3',3'-tetramethylspirobisindane with 1,4dicyanotetrafluorobenzene. Macromolecular Rapid Communications, 2008, 29(10): 783-788

35. Satilmis B, Budd P M. Base-catalysed hydrolysis of PIM-1: amide 
versus carboxylate formation. RSC Advances, 2014, 4(94): 52189 52198

36. Hao L, Liao K S, Chung T S. Photo-oxidative PIM-1 based mixed matrix membranes with superior gas separation performance. Journal of Materials Chemistry. A, Materials for Energy and Sustainability, 2015, 3(33): 17273-17281

37. Zhang L, Fang W, Jiang J. Effects of residual solvent on membrane structure and gas permeation in a polymer of intrinsic microporosity: insight from atomistic simulation. Journal of Physical Chemistry C, 2011, 115(22): 11233-11239

38. Mitra T, Bhavsar R S, Adams D J, Budd P M, Cooper A I. PIM-1 mixed matrix membranes for gas separations using cost-effective hypercrosslinked nanoparticle fillers. Chemical Communications, 2016, 52(32): 5581-5584

39. Abd Halim N S, Wirzal M D H, Bilad M R, Md Nordin N A H, Adi Putra Z, Sambudi N S, Mohd Yusoff A R. Improving performance of electrospun nylon 6,6 nanofiber membrane for produced water filtration via solvent vapor treatment. Polymers, 2019, 11(12): 2117

40. Rianjanu A, Kusumaatmaja A, Suyono E A, Triyana K. Solvent vapor treatment improves mechanical strength of electrospun polyvinyl alcohol nanofibers. Heliyon, 2018, 4(4): e00592

41. Brunetti A, Cersosimo M, Kim J S, Dong G, Fontananova E, Lee Y M, Drioli E, Barbieri G. Thermally rearranged mixed matrix membranes for $\mathrm{CO}_{2}$ separation: an aging study. International Journal of Greenhouse Gas Control, 2017, 61: 16-26

42. Bernardo P, Bazzarelli E, Tasselli F, Clarizia G, Mason C R, Maynard-Atem L, Budd P M, Lanc M, Pilnacek K, Vopicka O, Friess K, Fritsch D, Yampolskii Y P, Shantarovich V, Jansen J C. Effect of physical aging on the gas transport and sorption in PIM-1 membranes. Polymer, 2017, 113: 283-294

43. Scholes C A, Kanehashi S. Polymer of intrinsic microporosity (PIM-1) membranes treated with supercritical $\mathrm{CO}_{2}$. Membranes, 2019, 9(3): 1-12

44. Adymkanov S V, Yampol'skii Y P, Polyakov A M, Budd P M, Reynolds K J, McKeown N B, Msayib K J. Pervaporation of alcohols through highly permeable PIM-1 polymer films. Polymer Science, Series A, 2008, 50(4): 444-450

45. Robeson L M. The upper bound revisited. Journal of Membrane Science, 2008, 320(1): 390-400

46. Robeson L M. Correlation of separation factor versus permeability for polymeric membranes. Journal of Membrane Science, 1991, 62 (2): 165-185

47. Comesaña-Gándara B, Chen J, Bezzu C G, Carta M, Rose I, Ferrari M C, Esposito E, Fuoco A, Jansen J C, McKeown N B. Redefining the Robeson upper bounds for $\mathrm{CO}_{2} / \mathrm{CH}_{4}$ and $\mathrm{CO}_{2} / \mathrm{N}_{2}$ separations using a series of ultrapermeable benzotriptycene-based polymers of intrinsic microporosity. Energy \& Environmental Science, 2019, 12 (9): 2733-2740 